\title{
Efeito da Adição da Enzima Fitase sobre o Desempenho e a Digestibilidade Ileal de Nutrientes 1
}

\author{
Anel Atencio Tejedor², Luiz Fernando Teixeira Albino ${ }^{3}$, Horacio Santiago Rostagno³, \\ Flávio Medeiros Vieites ${ }^{2}$
}

\begin{abstract}
RESUMO - Conduziu-se um experimento utilizando 384 pintos de corte machos, Avian Farm, para se avaliar o efeito da fitase sobre o desempenho das aves e os coeficientes de digestibilidade ileal aparente da matéria seca (MS), da proteína bruta (PB), da energia bruta (EB), do fósforo (P) e do cálcio (Ca) e os valores de energia digestível ileal aparente (EDIap) e energia metabolizável aparente corrigida pelo balanço de nitrogênio (EMAn) de dietas à base de milho e farelo de soja com diferentes níveis de Ca e P disponível ( $\mathrm{P}_{\mathrm{d}}$ ). Foram utilizados pintos no período de 10 a 24 dias de idade, em arranjo fatorial 2 x 3, com oito repetições contendo oito aves cada. As dietas foram formuladas contendo dois níveis de Ca e $\mathrm{P}_{\mathrm{d}}$ : normal $\left(0,93 \% \mathrm{Ca} / 0,45 \% \mathrm{P}_{\mathrm{d}}\right)$ e baixo $\left(0,80 \% \mathrm{Ca} / 0,33 \mathrm{P}_{\mathrm{d}} \%\right)$ x três níveis de fitase (0 - controle, $500 \mathrm{FTU}$ - fitase 1 e 750 fitase - 2). Óxido crômico $(0,5 \%)$ foi adicionado às dietas a fim de se estimar o fator de indigestibilidade. A fitase 1 melhorou o ganho de peso em 3,4\% e a fitase 2, em 2,8\%. Ambas as enzimas melhoraram a conversão alimentar em $3 \%$ e a digestibilidade da PB, da EB, do P e do Ca. A adição das enzimas, também, melhorou significativamente a energia digestível ileal aparente $\left(\mathrm{EDI}_{\mathrm{ap}}\right)$, entretanto não se observou efeito da adição de fitase sobre $\mathrm{EMA}_{\mathrm{n}}$.
\end{abstract}

Palavras-chave: digestibilidade de nutrientes, enzima, fitase, frangos de corte, milho e farelo de soja

\section{Effect of Phytase Suplementation on the Performance and Ileal Digestibility of Nutrients}

\begin{abstract}
One experiment was conducted to evaluate the effect of microbial enzymes, phytase, on the performance of the birds and on the digestibility coefficient of dry mater (DM), crude protein (CP), phosphorus (P) and calcium (Ca) and the values of apparent ileal digestible of energy (AIDe) and nitrogen corrected apparent metabolizable energy (AMEn). A total of 384 Avian Farm male broiler chicks, 10 days old, during 14 d-trial were used in a factorial arrangement of $2 \times 3$, with eight replicates, eight chicks per unit were used. The diets were formulated to contain two levels of $\mathrm{Ca}$ and available $\mathrm{P}$ normal $\left(0.93 \% \mathrm{Ca} / 0.45 \% \mathrm{P}_{\mathrm{d}}\right)$ and $10 \mathrm{w}$ $\left(0.80 \% \mathrm{Ca} / 0.33 \% \mathrm{P}_{\mathrm{d}}\right) \mathrm{x}$ three level of phytase (o - control, $500 \mathrm{FTU}$ phytase -1 and 750 phytase 2$)$. Chromic oxide $(0,5 \%)$ was added to the diets, as an indigestible marker, to estimate ileal digestibility. Phytase 1 improve weight gain in $3.4 \%$ and phytase 2 in $2.8 \%$. Both enzymes improved feed:gain ratio in $3 \%$ and the digestibility of CP, E, P and Ca. Phytase addition, also, improved AIDe, however the enzyme did not improve the $\mathrm{EMA}_{\mathrm{n}}$.
\end{abstract}

Key Words: enzyme, phytase, corn-soyben meal, broilers chicks, nutrient digestibility

\section{Introdução}

No Brasil, aproximadamente $90 \%$ das dietas para aves são compostas de ingredientes de origem vegetal (milho e farelo de soja), sendo que a maior parte do fósforo presente nestes ingredientes se encontra na forma de ácido fítico, o qual é indisponível para aves. Segundo informações apresentadas no NATIONAL RESEARCH COUNCIL - NRC (1994), 30 a $40 \%$ do conteúdo total de $\mathrm{P}$ dos vegetais é considerado fósforo não-fítico.

A molécula de ácido fítico contém, aproximadamente, $28,2 \%$ de fósforo e sua propriedade antinutricional está além do não-aproveitamento do fósforo. Este ácido é um potente agente quelante de nutrientes como, por exemplo, proteínas, aminoácidos, amido e cátions (RAVINDRAN et al., 1999), e enzimas, como a pepsina, tripsina e $\alpha$-amilase (SEBASTIAN et al., 1998), de modo que a solubilidade e a digestibilidade são drasticamente reduzidas pela formação de complexos insolúveis.

Sob o ponto de vista da nutrição, a viabilização técnica das enzimas exógenas é marco importante, pois permite melhor aproveitamento de nutrientes. Incremento na utilização do fósforo, dos aminoácidos e da energia, por meio da utilização de enzimas fitase,

\footnotetext{
1 Parte da tese de Mestrado apresentada à UFV pelo primeiro autor.

2 Estudante de Doutorado do DZO - UFV, CEP: 36571-000, Viçosa - MG. E.mail: anel@alunos.ufv.br

3 Professor do DZO-UFV, CEP: 36571-000, Viçosa - MG. Bolsista do CNPq.
} 
representaria economia significativa no custo final da formulação das rações.

O fósforo e o nitrogênio são nutrientes essenciais em vários processos metabólicos dos animais; contudo, os movimentos ambientalistas têm forçado a redução destes nutrientes poluentes, que podem ser excretados em maior ou menor quantidade, dependendo da manipulação das fórmulas das dietas e das enzimas adicionadas.

Assim, é fundamental a realização de trabalhos de pesquisa visando conhecer o efeito da adição de enzimas microbianas exógenas sobre a digestibilidade dos nutrientes em diferentes ingredientes utilizados nas dietas para aves.

O objetivo do presente trabalho foi determinar o efeito da adição de fitase em dietas à base de milho e farelo de soja, com diferentes níveis de $\mathrm{Ca}$ e $\mathrm{P}_{\mathrm{d}}$, sobre o desempenho de frangos de corte; os coeficientes de digestibilidade ileal da MS, da PB, da EB, do $\mathrm{Ca}$ e do $\mathrm{P}$; e os valores de digestibilidade ileal e metabolizável aparente da energia, mediante ensaio biológico, utilizando pintos de corte.

\section{Material e Métodos}

Realizou-se um experimento de desempenho e ensaio biológico de digestibilidade, utilizando-se o "método tradicional de coleta total de excreta e de digesta do íleo". A temperatura média registrada durante o experimento foi de $23^{\circ} \mathrm{C}$ e a média das mínimas e máximas, de 18 e $28^{\circ} \mathrm{C}$, respectivamente.

Foram utilizados 384 pintos de corte, machos, da linhagem Avian Farm, com 10 dias de idade e peso médio de $183 \mathrm{~g}$. As rações (Tabela 1) à base de milho e farelo de soja foram formuladas para atender as exigências nutricionais das aves, de acordo com as recomendações de ROSTAGNO et al. (1996).

$\mathrm{O}$ delineamento experimental utilizado foi o inteiramente casualizado, em arranjo fatorial $2 \times 3$, com oito repetições de oito aves por unidade experimental. As dietas foram formuladas contendo dois níveis de Ca e $\mathrm{P}_{\mathrm{d}}$, $\operatorname{normal}\left(0,93 \% \mathrm{Ca} / 0,45 \% \mathrm{P}_{\mathrm{d}}\right)$ e baixo $\left(0,80 \% \mathrm{Ca} / 0,33 \% \mathrm{P}_{\mathrm{d}}\right)$, $v s$ três níveis de enzima fitase (0 para o controle, 500 FTU para fitase 1 e 750 FTU para fitase 2).

A enzima 1, com atividade enzimática de 3114 FTU/g, foi adicionada na dosagem de $160,6 \mathrm{~g} / \mathrm{kg}$ de ração (500 FTU/kg). A enzima 2, com atividade enzimática de $3594 \mathrm{FTU} / \mathrm{g}$, foi adicionada na proporção de 208,7 g/t (750 FTU/kg), de acordo com as recomendações da indústria.
Tabela 1 - Composição das dietas experimentais (\% matéria natural)

Table 1 - Composition of the reference diet (\% fed basis)

\begin{tabular}{|c|c|c|}
\hline \multirow{3}{*}{$\begin{array}{l}\text { Ingrediente } \\
\text { Ingredient }\end{array}$} & \multicolumn{2}{|c|}{$\begin{array}{l}\text { Nível Ca e } \mathrm{P}_{\mathrm{d}} \\
\text { Ca and } P_{a} \text { level }\end{array}$} \\
\hline & Normal & Baixo \\
\hline & Normal & Low \\
\hline & \multicolumn{2}{|c|}{-------- (\%) --------- } \\
\hline Milho & 56,68 & 57,88 \\
\hline Corn & & \\
\hline Farelo de soja, $45 \%$ PB & 37,00 & 36,80 \\
\hline Soybean meal, $45 \% C P$ & & \\
\hline Óleo vegetal & 2,13 & 1,73 \\
\hline Soybean oil & & \\
\hline Fosfato bicálcico & 1,807 & 1,150 \\
\hline Dicalcium phosphate & & \\
\hline Calcário & 0,940 & 1,000 \\
\hline Limestone & & \\
\hline Sal & 0,392 & 0,392 \\
\hline Salt & & \\
\hline Óxido crômico & 0,500 & 0,500 \\
\hline Chromic oxide & & \\
\hline Suplemento mineral ${ }^{1}$ & 0,050 & 0,050 \\
\hline Mineral premix & & \\
\hline Suplemento vitamínico ${ }^{2}$ & 0,100 & 0,100 \\
\hline Vitamin premix & & \\
\hline Dl-Metionina (99\%) & 0,180 & 0,178 \\
\hline DL-Methionine & & \\
\hline Anticoccidiano $^{3}$ & 0,050 & 0,050 \\
\hline Anticocidial & & \\
\hline Cloreto de colina ( $60 \%)$ & 0,060 & 0,060 \\
\hline Choline chloride & & \\
\hline Antioxidante ${ }^{4}$ & 0,010 & 0,010 \\
\hline Antioxidant & & \\
\hline Caulim & 0,100 & 0,100 \\
\hline Total & 100 & 100 \\
\hline Valores calculados & & \\
\hline Calculatedvalues & & \\
\hline Proteína bruta, $(\%)$ & 21,90 & 21,90 \\
\hline Crude protein & & \\
\hline Energia metabolizável & 3000 & 3000 \\
\hline Metabolizable energy kcal/kg & & \\
\hline Metionina + Cistina (\%) & 0,88 & 0,88 \\
\hline Methionine + Cys & & \\
\hline Lisina $(\%)$ & 1,20 & 1,20 \\
\hline Lysine & & \\
\hline $\mathrm{Ca}(\%)$ & 0,93 & 0,80 \\
\hline Fósforo disponível \% & 0,45 & 0,33 \\
\hline Available phosphorus & & \\
\hline
\end{tabular}

${ }^{1}$ Premix mineral contendo: Ferro (Iron), 100,0 g; Cobalto (Cobalt), 2,0 g; Cobre (Cupper), 20,0 g; Manganês (Manganese), 160 g; Zinco (Zinc) $100 \mathrm{~g}$; lodo (lodine), 2,0 g; Excipiente q.s.p., 500g.

2 Premix vitaminínico contendo: Vit. A, 10.000.000U.I; Vit. $D_{3}, 2.000 .000$ U.I; Vit. E, 30.000 U.I; Vit. $B_{1}$, 2,0 g; Vit. $B_{2}, 6,0$ g; Vit. $B_{6}, 4,0$ g; Vit. $\mathrm{B}_{12}, 0,015 \mathrm{~g}$; Ác. pantotênico (Pantothenic acid), $12,0 \mathrm{~g}$; Biotina (Biotin), $0,1 \mathrm{~g}$; Vit. K $\mathrm{K}_{3}, 3,0 \mathrm{~g}$; Ác. fólico (Folic acid), 1,0 g; Ác. nicotínico (Nicotinic acid), 50,0 g; Selênio (Selenium), 250,0 mg; Excipiente q.s.p., $1000 \mathrm{~g}$.

3 Maduramicina.

${ }^{4}$ Butil hidroxi tolueno $99 \%$. 
804 Rev. bras. zootec.

O óxido crômico, utilizado como indicador fecal, para a determinação dos coeficientes de digestibilidade, foi misturado com os demais ingredientes na concentração de $0,5 \%$.

Até os 10 dias de idade, as aves receberam ração inicial para frangos de corte e ficaram alojadas em um galpão de alvenaria. Após esse período, os pintos foram transferidis para baterias frias tipo "PETER SIME", com $225 \mathrm{~cm}^{2}$ de área $(45 \mathrm{~cm}$ de largura, $50 \mathrm{~cm}$ de comprimento e $40 \mathrm{~cm}$ de altura), em estrutura metálica, constituídas de compartimentos distribuídos em dois andares. Estas baterias, em número de quatro, estavam dispostas em uma sala de $68 \mathrm{~m}^{2}$, com 2,80 $\mathrm{m}$ de pé direito e grandes janelas de vidro. As aves receberam luz natural e, ou, artificial durante 24 horas. Para maior conforto dos animais, foram utilizados dois aquecedores elétricos e uma campânula a gás, à noite, durante todo o período experimental. As aves receberam água e ração experimental à vontade.

As aves e dietas foram pesadas no início e no final do experimento, para avaliação do ganho de peso e da conversão alimentar. Dos 19 a 24 dias de idade, realizou-se a coleta total de excretas, com intervalo de 12 horas, para o cálculo dos valores de energia metabolizável aparente, corrigida para o balanço de nitrogênio (EMAn).

Aos 25 dias de idade, todas as aves de cada repetição foram abatidas com deslocação cervical e imediatamente disseccionadas para obtenção da digesta da porção do íleo terminal, desde um ponto $5 \mathrm{~cm}$ antes da junção íleo-cecólica até $15 \mathrm{~cm}$ em direção anterior ou em direção ao jejuno. Este segmento foi seccionado transversalmente e seu conteúdo, retirado e colocado dentro de um copo plástico.

As digestas e excretas coletadas foram acondicionadas em bandejas plásticas devidamente identificadas, pesadas e, posteriormente, armazenadas em congelador. Após, as amostras foram présecas a $65^{\circ} \mathrm{C}$, por 72 horas, em estufa de ventilação forçada, e moídas em moinhos com $1 \mathrm{~mm}$ de mesh e imediatamente preparadas para análise laboratorial de oxido crômico, matéria seca, nitrogênio, energia bruta, fósforo e cálcio.

As análises químicas das excretas, digestas e rações foram realizadas no Laboratório de Nutrição Animal, por intermédio da metodologia descrita por SILVA (1990).

Uma vez obtidos os resultados de análises laboratoriais das dietas, da digesta e das excretas, foram calculados os coeficientes de digestibilidade ileal aparente da matéria seca, da proteína bruta, da energia bruta, do fósforo e do cálcio; os valores de energia digestível ileal aparente com base nos níveis de cromo na dieta e digesta; e o fator de indigestibilidade. Os valores de EMAn das rações foram calculados por meio de equações propostas por MATTERSON et al. (1965).

Os dados experimentais obtidos foram submetidos à análise de variância e à comparação de médias, utilizando-se o teste Student-Newman-Keuls (SNK) do programa estatístico SAS (1996).

\section{Resultados e Discussão}

Não se observou interação entre os diferentes níveis de $\mathrm{Ca}$ e $\mathrm{P}_{\mathrm{d}}$ e a adição de fitase nas dietas, para nenhum dos parâmetros estudados. Entretanto, a adição da fitase melhorou $(\mathrm{P}<0,05)$ o ganho de peso e a conversão alimentar (Tabela 2).

A adição das fitases 1 e 2 na dieta melhorou em 3,4 e $2,8 \%$, respectivamente, o ganho de peso $(\mathrm{P}<0,05)$. A conversão alimentar foi melhorada $(\mathrm{P}<0,05) \mathrm{em}$ $3 \%$ por ambas as enzimas. Não houve diferença $(\mathrm{P}>0,05)$ entre as fitases 1 e 2 . Estes resultados estão coerentes com os encontrados por vários pesquisadores (YI et al., 1996; BIEHL e BAKER, 1997; QIAN et al., 1997; SEBASTIAN et al., 1997; KERSEY et al., 1998; NAMKUNG e LEESON, 1999; e RAVINDRAN et al., 1999). No entanto, SOHAIL e ROLAND (1999), utilizando níveis de $\mathrm{P}_{\mathrm{d}}$ normais e baixos $(0,325$ e $0,225 \%)$ e três níveis de fitase (0, 300 e $600 \mathrm{FTU})$, não observaram melhora no desempenho. Os autores relataram que as características ósseas são parâmetros mais sensíveis que o desempenho para se avaliar o efeito da fitase.

A diminuição dos níveis de Ca e $\mathrm{P}_{\mathrm{d}}(0,80 \% \mathrm{Ca} /$ $\left.0,33 \% \mathrm{P}_{\mathrm{d}}\right)$ não afetou $(\mathrm{P}>0,05)$ o ganho de peso e a conversão alimentar, embora tenha sido observada melhora $(\mathrm{P}>0,05)$ nos coeficientes de digestibilidade da MS, PB, Ca, P e nos valores de EDIap (Tabela 3 e 4) nas rações com níveis normais de Ca e $P_{d}$, a qual não foi traduzida em melhora no desempenho. Estes resultados provavelmente estão relacionados ao efeito cumulativo do fósforo e cálcio, fornecidos durante os 10 primeiros dias de vida, quando os animais receberam uma dieta com níveis de $\mathrm{Ca}$ e $\mathrm{P}_{\mathrm{d}}$ dentro do requerimento, concordando com os achados de SOHAIL e ROLAND (1999).

A adição de ambas as fitases nas dietas não afetou o consumo de ração $(\mathrm{P}>0,05)$, porém as dietas com níveis de $\mathrm{Ca}$ e $\mathrm{P}_{\mathrm{d}}$ baixo promoveram consumo $2 \%$ 
Tabela 2 - Efeito da adição da fitase sobre o desempenho de frangos de corte Table 2 - Effect of phytase suplementation on broilers performance

\begin{tabular}{|c|c|c|c|c|c|c|c|c|c|}
\hline \multirow[t]{2}{*}{$\begin{array}{l}\text { Enzima } \\
\text { Enzyme }\end{array}$} & \multicolumn{3}{|c|}{$\begin{array}{l}\text { Ganho de peso }(\mathrm{g}) \\
\text { Body weight gain } \\
\text { Nível Ca e } \mathrm{P}_{\mathrm{d}}^{1} \\
\text { Ca and } P_{a} \text { level } \\
\end{array}$} & \multicolumn{3}{|c|}{$\begin{array}{c}\text { Consumo de ração }(\mathrm{g}) \\
\text { Feed intake } \\
\text { Nível Ca e } \mathrm{P}_{\mathrm{d}} \\
\text { Ca and } P_{a} \text { level }\end{array}$} & \multicolumn{3}{|c|}{$\begin{array}{c}\text { Conversão alimentar } \\
\text { Feed:gain ratio } \\
\text { Nível Ca e } \mathrm{P}_{\mathrm{d}} \\
\text { Ca and } P_{a} \text { level }\end{array}$} \\
\hline & $\begin{array}{l}\text { Normal } \\
\text { Normal }\end{array}$ & $\begin{array}{c}\text { Baixo } \\
\text { Low }\end{array}$ & $\begin{array}{c}\text { Média } \\
\text { Mean }\end{array}$ & $\begin{array}{l}\text { Normal } \\
\text { Normal }\end{array}$ & $\begin{array}{l}\text { Baixo } \\
\text { Low }\end{array}$ & $\begin{array}{c}\text { Média } \\
\text { Mean }\end{array}$ & $\begin{array}{l}\text { Normal } \\
\text { Normal }\end{array}$ & $\begin{array}{l}\text { Baixo } \\
\text { Low }\end{array}$ & $\begin{array}{c}\text { Média } \\
\text { Mean } \\
\end{array}$ \\
\hline $\begin{array}{l}\text { Controle } \\
\text { Control }\end{array}$ & 613 & 619 & $616^{\mathrm{B}}$ & 1,011 & 1,030 & 1,021 & 1,66 & 1,67 & $1,66^{\mathrm{A}}$ \\
\hline $\begin{array}{l}\text { Fitase } 1 \\
\text { Phytase } 1\end{array}$ & 633 & 641 & $637^{\mathrm{A}}$ & 1,015 & 1,043 & 1,029 & 1,61 & 1,61 & $1,61^{\mathrm{B}}$ \\
\hline $\begin{array}{l}\text { Fitase } 2 \\
\text { Phytase } 2\end{array}$ & 635 & 631 & $633^{\mathrm{A}}$ & 1,017 & 1,026 & 1,022 & 1,60 & 1,62 & $1,61^{\mathrm{B}}$ \\
\hline Média (Mean) & 627 & 631 & & $1,014^{\mathrm{b}}$ & $1,033^{\mathrm{a}}$ & & 1,62 & 1,64 & \\
\hline Anova & & & & & $\begin{array}{l}\text { ilidade } \\
\text { abilitity }\end{array}$ & $\begin{array}{l}\text { teste } \mathrm{F} \\
\text { test }\end{array}$ & & & \\
\hline $\begin{array}{l}\text { Ca e } \mathrm{P}_{\mathrm{d}} \\
C a \text { and } P_{a}\end{array}$ & & 0,49 & & & 0,04 & & & 0,29 & \\
\hline $\begin{array}{l}\text { Fitase (Fit) } \\
\text { Phytase }\end{array}$ & & $<0,01$ & & & 0,73 & & & $<0,01$ & \\
\hline $\begin{array}{l}\text { Ca e } \mathrm{P}_{\mathrm{d}} * \text { Fit } \\
\text { Ca and } P_{a} \\
\mathrm{CV}(\%)\end{array}$ & & 0,64 & & & 0,71 & & & 0,64 & \\
\hline
\end{tabular}

ab Médias seguidas por letras minúsculas na mesma linha são diferentes pelo teste $F(P<0,05)$.

$A B$ Médias seguidas por letras maiúsculas na mesma coluna são diferentes pelo teste $S N K(P<0,05)$.

1 Ca e $\mathrm{P}_{\mathrm{d}}$ : normal = 0,93\%Ca/0,45\% $\mathrm{P}_{\mathrm{d}}$ e baixo $=0,80 \% \mathrm{Ca}: 0,33 \% \mathrm{P}_{\mathrm{d}}$.

ab Means in the same line followed by different letter are different $(P<.05)$ by Newman-Keuls test.

$\mathrm{AB}$ Means in the same column followed by different letter are different $(P<.05)$ by Newman-Keuls test.

$1 \mathrm{Ca}$ and $P_{a}$ : normal $=.93 \% \mathrm{Ca} / .45 \% P_{a}$ and low $=.80 \% \mathrm{Ca}: .33 \% P_{a}$.

mais elevado $(\mathrm{P}<0,05)$. Este aumento no consumo de ração, das dietas com níveis baixos de $\mathrm{Ca}$ e $\mathrm{Pd}$, talvez ocorreu com o intuito de compensar a deficiência de $\mathrm{Ca}$ e $\mathrm{P}_{\mathrm{d}}$

A ausência de interação significativa dos níveis de $\mathrm{Ca}$ e $\mathrm{P}_{\mathrm{d}}$ vs fitase, neste estudo, indica que a influência da fitase sobre o desempenho não dependeu dos níveis da Ca e $\mathrm{P}_{\mathrm{d}}$.

$\mathrm{O}$ aumento no ganho de peso pela adição das enzimas pode ser explicado por incremento encontrado na digestibilidade ileal da $\mathrm{PB}$, do $\mathrm{P}$, do $\mathrm{Ca}$ e dos valores da EDIap (Tabela 3 e 4). Estes resultados concordam com os encontrados por diversos autores (BROZ et al., 1994; PERNEY et al., 1993; SEBASTIAN et al., 1996; SEBASTIAN et al., 1997; KERSEY et al., 1998; NAMKUNG e LEESON, 1999; e RAVINDRAN et al., 1999).

Os coeficientes de digestibilidade ileal aparente da matéria seca (MS), da proteína bruta (PB), da energia bruta (EB), do fósforo $(\mathrm{P})$ e do cálcio $(\mathrm{Ca})$ são apresentados na Tabela 3.

Não foi observada interação $(\mathrm{P}<0,05)$ para nenhum dos parâmetros estudados. A adição da fitase aumentou $(\mathrm{P}<0,05)$ a digestibilidade ileal de $\mathrm{PB}, \mathrm{EB}$, $\mathrm{P}$ e $\mathrm{Ca}$, mas não influiu na digestibilidade da MS. A fitase 1 melhorou os coeficientes de digestibilidade da PB (1\%), EB (1\%), do Ca $(3,5 \%)$ e do P $(3,5 \%)$ e a fitase 2 melhorou a digestibilidade da $\mathrm{PB}(1,7 \%), \mathrm{EB}$ $(1,2 \%)$, do $\mathrm{Ca}(5 \%)$ e do $\mathrm{P}(4 \%)$ em relação ao controle. Os efeitos positivos da adição da fitase estão de acordo com os encontrados por vários pesquisadores (NELSON et al., 1971; YI et al., 1996; SEBASTIAN et al., 1996, 1997; QIAN et al., 1997; KERSEY et al., 1998; NAMKUNG e LEESON, 1999; e RAVINDRAN et al., 1999).

A molécula de ácido fítico tem capacidade de se ligar à proteína, em meios ácido, alcalino e neutro (Anderson, 1985, citado por SEBASTIAN et al. (1997), e reduzir a atividade da pepsina, tripsina e aamilase (SEBASTIAN et al., 1998). Espera-se melhorar o aproveitamento de proteína e aminoácidos, por meio da quebra destes complexos nutritivos, pela utilização de fitase microbiana nas dietas.

$\mathrm{Na}$ análise dos diferentes níveis de $\mathrm{Ca}$ e $\mathrm{P}_{\mathrm{d}}$, observou-se efeito significativo $(\mathrm{P}<0,05)$ para todos os parâmetros estudados. Os coeficientes de 


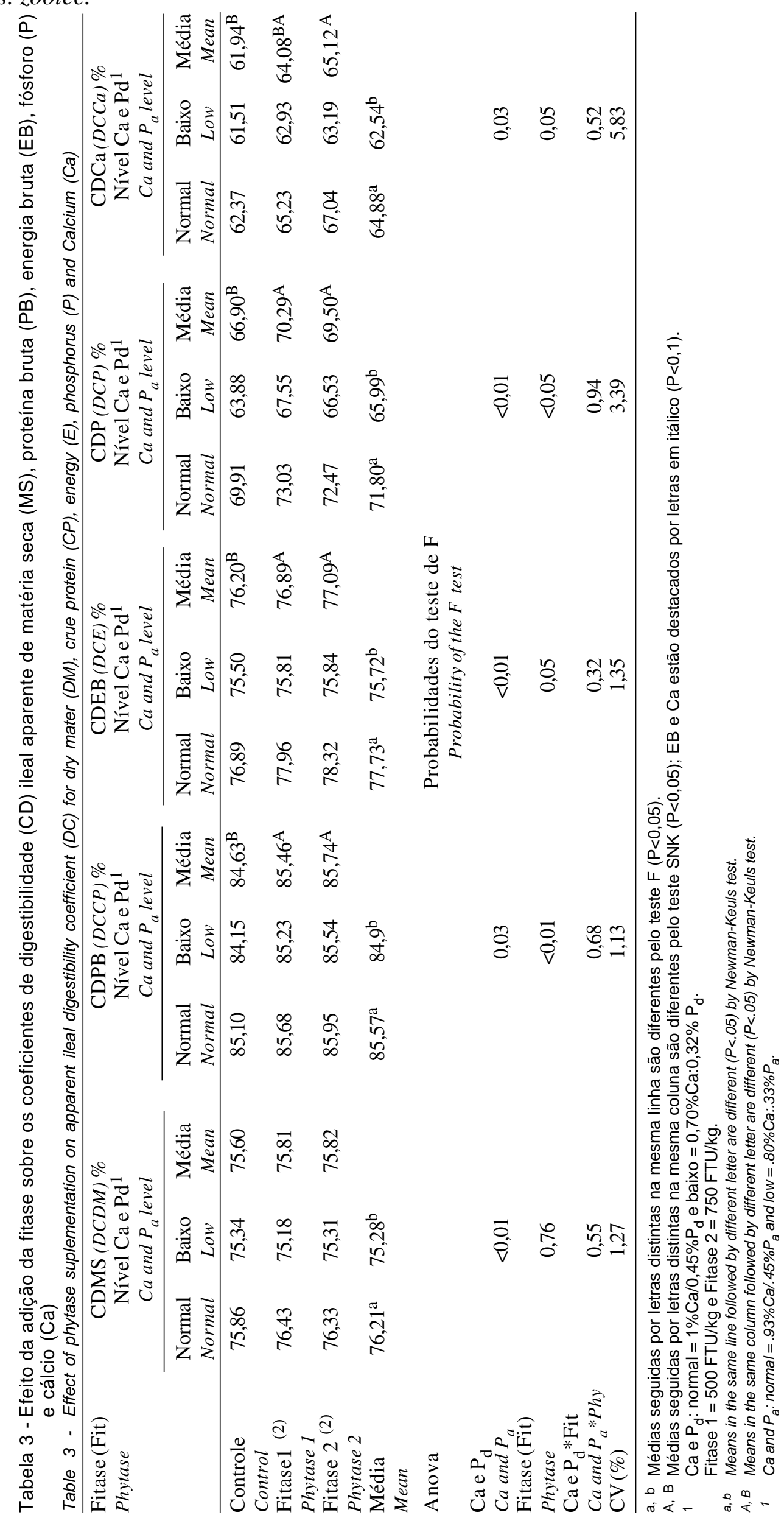


TEJEDOR et al.

digestibilidade dos diferentes parâmetros avaliados diminuíram $(\mathrm{P}<0,05)$ com a redução nos níveis de $\mathrm{Ca}$ e $P_{d}$ da ração. Estes resultados foram semelhantes aos encontrados por SEBASTIAN et al. (1996) e QIAN et al. (1997). A relação Ca e $\mathrm{P}_{\mathrm{d}}$ nas dietas com níveis normais de $\mathrm{Ca}$ e $\mathrm{P}_{\mathrm{d}}$ foi de 2,07:1 (relação recomendada pelo NRC, 1994) e das dietas com níveis baixos de Ca e Pd foi de 2,4 : 1 (relação acima da recomendada).

Pode-se inferir, com base nestes resultados, que o alto nível de cálcio em relação ao fósforo (relação $\mathrm{Ca}: \mathrm{P}-2,4: 1$ ) nas dietas com níveis de Ca e $\mathrm{P}$ baixos prejudicou o efeito da fitase. Esperava-se que as dietas com níveis de $\mathrm{Ca}$ e $\mathrm{P}_{\mathrm{d}}$ baixos apresentassem coeficientes de digestibilidade maiores, por haver menor teor de cálcio e fósforo no trato gastrointestinal. SEBASTIAN et al. (1996) e QIAN et al. (1997) observaram resultados semelhantes utilizando diferentes relações $\mathrm{Ca}$ e $\mathrm{P}_{\mathrm{d}}$ em dietas para pintos de corte.

Portanto, a relação Ca: $\mathrm{P}_{\mathrm{d}}$ é, provavelmente, fator limitante, na redução da atividade da fitase. De acordo com MCCUAIG et al. (1972), níveis elevados de $\mathrm{Ca}$, em relação ao fósforo total na dieta, competem pelo sítio de ligação da fitase, diminuindo o máximo da atividade da enzima. WISE (1983) relatou que o Ca pode se complexar ao fitato, formando complexos Ca-fitato, os quais precipitam, ficando indisponível para a atuação da enzima. Ambos os fatores prejudicam o máximo da atividade da fitase.

Alguns fatores são extremamente importantes para que sejam alcançados os máximos resultados da atividade da fitase, entre eles a relação Ca:Pt ideal, não-definida na literatura até o presente, e a definição do ponto máximo em que a porcentagem de $\mathrm{P}_{\mathrm{d}}$ pode ser reduzida (QIAN et al., 1996; YI et al., 1996; e SEBASTIAN et al., 1996).

A adição das fitases melhorou significativamente $(\mathrm{P}<0,05)$ a energia digestível ileal aparente $\left(\mathrm{EDI}_{\mathrm{ap}}\right)$, não havendo diferença entre as fontes de fitase. Não se observou efeito da adição de fitase sobre EMA $_{n}$ (Tabela 4).

Os resultados para a EMAn diferem daqueles

Tabela 4 - Efeito da adição da fitase sobre os valores de energia digestível ileal aparente (EDlap) e de energia metabolizável aparente corrigida para nitrogênio $\left(E M A_{n}\right)$, expressos em $\mathrm{kcal} / \mathrm{kg}$ de matéria seca

Table 4 - Effect of enzyme suplementation on the value of apparent ileal digestible energy (apIDE) and apparent metabolizable energy corrected by nitrogen $\left(A M E_{n}\right)$, express in $\mathrm{kcal} / \mathrm{kg}$ dry matter

\begin{tabular}{|c|c|c|c|c|c|c|}
\hline \multirow{3}{*}{$\begin{array}{l}\text { Fitase }^{1}(\mathrm{~F}) \\
\text { Phytase }\end{array}$} & \multicolumn{3}{|c|}{$\mathrm{EDI}_{\mathrm{ap}}(\mathrm{apIDE})$} & \multicolumn{3}{|c|}{$\mathrm{EMA}_{\mathrm{n}}\left(\mathrm{AME}_{\mathrm{n}}\right)$} \\
\hline & \multicolumn{6}{|c|}{$\begin{array}{l}\text { Nível Ca e } \mathrm{P}_{\mathrm{d}}^{1} \\
\text { Ca and } P_{a} \text { level }\end{array}$} \\
\hline & $\begin{array}{l}\text { Normal } \\
\text { Normal }\end{array}$ & $\begin{array}{l}\text { Baixo } \\
\text { Low }\end{array}$ & $\begin{array}{l}\text { Média } \\
\text { Mean }\end{array}$ & $\begin{array}{l}\text { Normal } \\
\text { Normal }\end{array}$ & $\begin{array}{l}\text { Baixo } \\
\text { Low }\end{array}$ & $\begin{array}{l}\text { Média } \\
\text { Mean }\end{array}$ \\
\hline $\begin{array}{l}\text { Controle } \\
\text { Control }\end{array}$ & 3478 & 3398 & $3438^{B}$ & 3403 & 3349 & $3376^{\mathrm{A}}$ \\
\hline $\begin{array}{l}\text { Fitase } 1 \\
\text { Phytase } 1\end{array}$ & 3526 & 3412 & $3469^{A}$ & 3394 & 3354 & $3374^{\mathrm{A}}$ \\
\hline $\begin{array}{l}\text { Fitase } 2 \\
\text { Phytase } 2\end{array}$ & 3543 & 3413 & $3478^{\mathrm{A}}$ & 3398 & 3335 & $3367^{\mathrm{A}}$ \\
\hline Média & $3516^{\mathrm{a}}$ & $3408^{b}$ & & $3398^{a}$ & $3346^{\mathrm{b}}$ & \\
\hline
\end{tabular}

Mean

Anova

Probabilidade do teste de F

Ca e $\mathrm{P}_{\mathrm{d}}$

$C a$ and $P_{a}$

Fitase

Phytase

Ca e $\mathrm{P}_{\mathrm{d}^{*}}$ Fit

Ca and $P_{a} *$ Phytase

CV $(\%)$

Probability F test

$\begin{array}{lc}<0,01 & <0,01 \\ 0,05 & 0,86 \\ 0,32 & 0,83 \\ 1,34 & 1,65\end{array}$

\footnotetext{
a, b Médias seguidas por letras distintas na mesma linha são diferentes pelo teste $F(P<0,05)$.

$A, B$ Médias seguidas por letras distintas na mesma coluna são diferentes pelo teste SNK $(P<0,01)$.

1 Ca e $\mathrm{P}_{\mathrm{d}}$ : normal $=0,93 \% \mathrm{Ca} / 0,45 \% \mathrm{P}_{\mathrm{d}}$ e baixo $=0,80 \% \mathrm{Ca} / 0,33 \% \mathrm{P}_{\mathrm{d}}$.

Fitase $1=500 \mathrm{FTU} / \mathrm{kg}$ e Fitase $2=750 \mathrm{FTU} / \mathrm{kg}$.

a, $b$ Means in the same line followed by different letter are different $(P<.05)$ by Newman-Keuls test.

A, B Means in the same column followed by different letter are different $(P<.05)$ by Newman-Keuls test.

1 Ca and $P_{a}$ : normal $=.93 \% \mathrm{Ca} / .45 \% P_{a}$ and low $=.80 \% \mathrm{Ca}: 33 \% P_{a}$.
} 
808 Rev. bras. zootec.

obtidos por NAMKUNG e LEESON (1999), que encontraram melhora $(\mathrm{P}<0,01)$ de $1 \%$ nos valores de EMA $_{\mathrm{n}}$. RAVINDRAN et al. (1999) encontraram aumento de 3,5\% nos valores de EMA.

Os níveis de Ca e $\mathrm{P}_{d}$ influenciaram as $\mathrm{EDI}_{\mathrm{ap}}$ e EMAn, que apresentaram menores $(\mathrm{P}<0,05)$ valores nas rações com menores concentrações de $\mathrm{Ca}$ e $\mathrm{P}_{\mathrm{d}}$.

A melhora observada no desempenho das aves e nos valores de digestibilidade ileal de nutrientes nas dietas é indicativo da efetividade da fitase como aditivo nas rações de aves. A inclusão de fitase em dietas práticas das aves pode levar os nutricionistas a utilizar menores níveis de cálcio e fósforo inorgânico nas rações iniciais de frango. Entretanto, trabalhos devem ser realizados para determinar, com precisão, o nível de fitase exógena e ácido fítico e o nível e a relação $\mathrm{Ca}$ :Pt que permitem o máximo desempenho das aves.

\section{Conclusões}

A adição de fitase em dieta inicial à base de milho e farelo de soja, para pintos de corte, melhorou o ganho de peso e a conversão alimentar. A melhora $(\mathrm{P}<0,05)$ da fitase 1 (500 FTU) foi de 3,4\% e da fitase 2 (750 FTU), de 2,8\% para o ganho de peso. Ambas melhoraram a conversão alimentar em $3 \%$.

A adição da fitase melhorou a digestibilidade do cálcio e fósforo, bem como a digestibilidade da energia bruta e proteína bruta e os valores de energia digestível ileal aparente.

\section{Referências Bibliográficas}

BIEHL, R.R., BAKER, D.H. 1997. Microbial phytase improves amino acid utilization in young chicks fed diets based on soybean meal, but not in diets based on peanut meal. Poult. Sci., 76:355-360.

BROZ, J., OLDALE, P., PERRIN-VOLTZ, A.H. 1994. Effects of supplemental phytase on performance and phosphorus utilization in broiler chickens fed a low phosphorus diet without addition of inorganic phosphates. Br. Poult. Sci., 35(2):273-280.

KERSEY, J.H., SALEH, E.A., STILBORN, H.L. et al. 1998. Effect of dietary phosphorous level, high available phosphorus corn, and microbial phytase on performance and fecal phosphorus content. 1. Broiler grown 1 to $21 \mathrm{~d}$ in battery pens. Poult. Sci., 77:71 (suppl.1) (abstract.).

MATTERSON, L.D., POTTER, L.M., STUTZ, N.W. 1965. The metabolizable energy offeeds ingredient for chickens. Storrs. University of Connecticut - Agricultural Experiment Station. 11p. (Research Report, 7).

MCCUAIG, L.W., DAVIS, M.I., MOTZOK, I. 1972. Intestinal alkaline phosphatase and phytase o chicks: effect of dietary magnesium, calcium, phosphorus and thyroactive casein. Poult. Sci., 51:526-530.
NAMKUNG, H., LEESON, S. 1999. Effect of phytase Enzyme on dietary Nitrogen-corrected apparent metabolizable energy and ileal digestibility of nitrogen and amino acids in broiler chcks. Poult. Sci., 78:1317-1319.

NATIONAL RESEARCH COUNCIL - NRC. 1994. Nutrient requirements of poultry. 9.ed. Washington: National Academy of Sciences. 155p.

NELSON, T.S., SHIEH, T.R., WODZINSKI, R.J. 1971. Effect of supplemental phytase on the utilization of phytate phophorus by chicks. J. Nut., 101:1289-1292.

PERNEY, K.M., CANTOR, A.H., STRAW, M.L. et al. 1993. The effect of dietary on growth performance and phosphorus utilization of broiler chicks. Poult. Sci., 72:2106-2114.

QIAN, H., KORNEGAY, E.T., DENBOW, D.M. 1996. Phosphorous equivalence of microbial phytase in turkey diets as influenced by calcium to phosphorous ratios and phosphorus levels. Pout. Sci., 75:68-81.

QIAN, H., KORNEGAY, T., DENBOW, D.M. 1997. Utilization of phytase phosphorus and calcium as influenced by microbial phytase, cholecalciferol, and the calcium:total phosphorus ratio in broiler diets. Poult. Sci., 78:37-46.

RAVINDRAN, V., CABAHUG, S., RAVINDRAN, G., BRYDEN, L. 1999. Influence of microbial phytase on apparent ileal amino acid digestibility of feedstuffs for broiler. Poult. Sci., 78:699-706.

ROSTAGNO, H.S., BARBARINO JR., P. BARBOZA, W. Exigências nutricionais das aves determinadas no Brasil. in: SIMPÓSIO INTERNACIONAL SOBRE EXIGÊNCIAS NUTRICIONAIS DE AVES E SUÍNOS, 1996, Viçosa, MG. Anais... Viçosa, MG: UFV, 1996. p.361-388.

STATISTICAL ANALYSES SYSTEM - SAS. 1996. North Caroline State University, Cary, NC, USA Institute Inc.

SEBASTIAN, S., TOUCHBURN, S.P., CHAVEZ, E.R. et al. 1996. Efficacy of supplemental microbial phytase at different dietary calcium levels on growth performance and mineral utilization of broiler chickens. Poult. Sci., 75:1516-1523.

SEBASTIAN, S., TOUCHBURN, S.P., CHAVEZ, E.R.et al. 1997. Aparent digestibility of protein and amino acids in broiler chickens fed a corn-soybean diet supplemented with microbial phytase. Poult. Sci., 78:1760-1769.

SEBASTIAN, S., TOUCHBURN, S.P., CHAVEZ, E.R. 1998. Implications of phytic acid and supplemental microbial phytase in poultry nutrition: a review. World's Poult. Sci. J., 54:27-47.

SILVA, D.J. 1990. Análise de alimentos (Métodos químicos e biológicos). Viçosa: UFV. 166p.

SOHAIL, S.S., ROLAND, D.A. 1999. Influence of supplemental phytase on performance of broilers four to six of age. Poult. Sci., 78:550-555.

WISE, A. 1983. Dietary factors determining the biological activities of phytase. Nut. Abst. Review, 53:791-806.

YI, Z., KORNEGAY, E.T., RAVINDRAN, J. et al. 1996. Improving phytase phosphorus availability in corn and soybean meal for broiler using microbial phytase and calculation of phosphorus equivalency values for phytase. Poult. Sci., 75:240-249.

Recebido em: 14/07/00 Aceito em: 13/12/00 